Archived version from NCDOCKS Institutional Repository http://libres.uncg.edu/ir/asu/

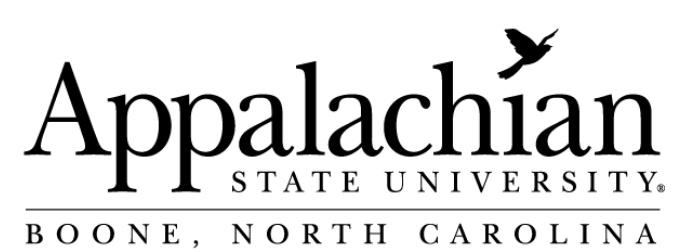

\title{
National Union Catalog: Asset or Albatross?
}

\author{
By: John P. Abbott \& Allan Scherlen
}

No Abstract

Abbot, John \& Allen Scherlen (2012) National Union Catalog: Asset or Albatross? Charleston Conference Proceedings (DOI 10.5703/1288284315083) Perdue Univesity e-pubs 


\section{National Union Catalog: Asset or Albatross?}

John P. Abbott, Coordinator of Collection Management, Appalachian State University

Allan Scherlen, Social Science Librarian, Appalachian State University

\section{Overview of the Presentation}

A fitting alternate title for this presentation would be "Archeology or Urban Renewal: Midsize academic libraries consider the fate of their predigital research tools." This presentation considers how the challenges faced by libraries in midsize institutions differ from those at larger research institutions. Midsize academic libraries face unique challenges particularly in some of the greyer areas of collection management: predigital resources perceived by some faculty to be essential, but which may be more appropriately held or archived by R-1 institutions than midsize. The presentation then addresses the example of de-selection decisions regarding voluminous paper sets of pre-digital finding aids with a focus upon the presenters' study of midsize library attitudes toward retaining or weeding the iconic National Union Catalog, Pre-1956 Imprints.

\section{The Unique Mission of Libraries in Midsize Universities}

Midsize libraries are often conceptualized as being smaller-scale versions of their R-1 university brethren. The presenters contend that midsize academic libraries have a unique role and set of challenges that differentiates them from the larger research or ARL libraries. Solutions and obligations related R-1 libraries may or may not fit well with the mission of midsize libraries. Midsize libraries, therefore, need to look to their own peer group for best practice solutions and opportunities.

Midsize academic libraries are usually not the libraries-of-record for their state or region and may not be bound to retain the same historic collection materials that a research library is expected to have and to hold. When compared to R-1 libraries, midsized libraries generally have smaller budgets and face greater challenges in balancing efficiency (use of the budget) and adequacy (a collection that supports faculty research). Midsize university faculty members work in an environment of rising expectations for their research production, and consequently, they expect their libraries to support them in meeting those expectations. Other demands on midsize libraries come from the changing nature of library space which is increasingly repurposed from collections to seating, computer labs, and housing of non-library units in the building. Again, the budget to accommodate those physical space demands is modest in midsized libraries.

\section{The Big Sets}

The repurposing of library space, as well as the need to plan for better use of existing space, brings existing collections under new examination. These materials may have escaped scrutiny in the past. Appalachian State University, the presenters' midsize institution, faces these demands, but finds little peer-group information in the literature to guide them. To reclaim space, we began to assess large, pre-digital, multi-volume sets for their continued use and utility. A walk through the library stacks revealed several candidates for deselection consideration:

- Many shelves of law materials now accessed via Westlaw and/or LexisNexis.

- Extensive back runs of index and abstract services now searched online.

- Many shelves of printed journals duplicated in JSTOR and other e-journal services.

- Large sets currently accessible in multiple formats, such as the U.S. Congressional Serials Set.

- Pre-digital reference and cataloging tools like the Cumulative Book Index and the National Union Catalog, pre-1956 imprints.

In-house use statistics indicate these paper sets receive little current use while occupying large footprints in the physical collection. But each of these sets or collections has deep roots that are 
not easily pulled: it may represent an earlier large monetary investment by the library; it may hold iconic status in libraries or the academy; it may have "just in case" reference potential; or it may have unknown users among our student and faculty patrons.

\section{The Case of the National Union Catalog, Pre-1956 Imprints (NUC)}

The presenters found the National Union Catalog, pre-1956 imprints (NUC) to be an excellent example of a set contributing to the dilemma facing midsize academic libraries: trying to balance the provision of adequate resources for faculty research while operating within a limited midsize library budget. The NUC has over 750 oversized volumes and occupies more than 125 feet of linear shelf space. Stacked end-on-end, the set would be taller than New York's Trump Tower. Unbound, the individual pages would cover much of Manhattan Island. completion in 1981, it received heavy use by librarians and researchers. For many librarians of that era who are still practicing, the set holds almost inviolable iconic status.

\section{The Presenters' NUC Study}

The presenters, cognizant of the dilemma facing midsize libraries such as theirs, were hesitant to too swiftly remove a set as grand and iconic as the NUC. Rather than act hastily, the presenters decided to survey peers to discover how many still kept or had discarded the NUC and why. Using a SurveyMonkey questionnaire, they asked midsize academic library collection development and cataloging librarians to respond to 29 questions about their library's size, budget, space concerns, retention of the NUC, the nature of their current pre-1956 acquisitions, and if they had discarded the set what were the reactions.Sixty-two usable responses were received. Approximately threequarters of the respondents had retained the NUC

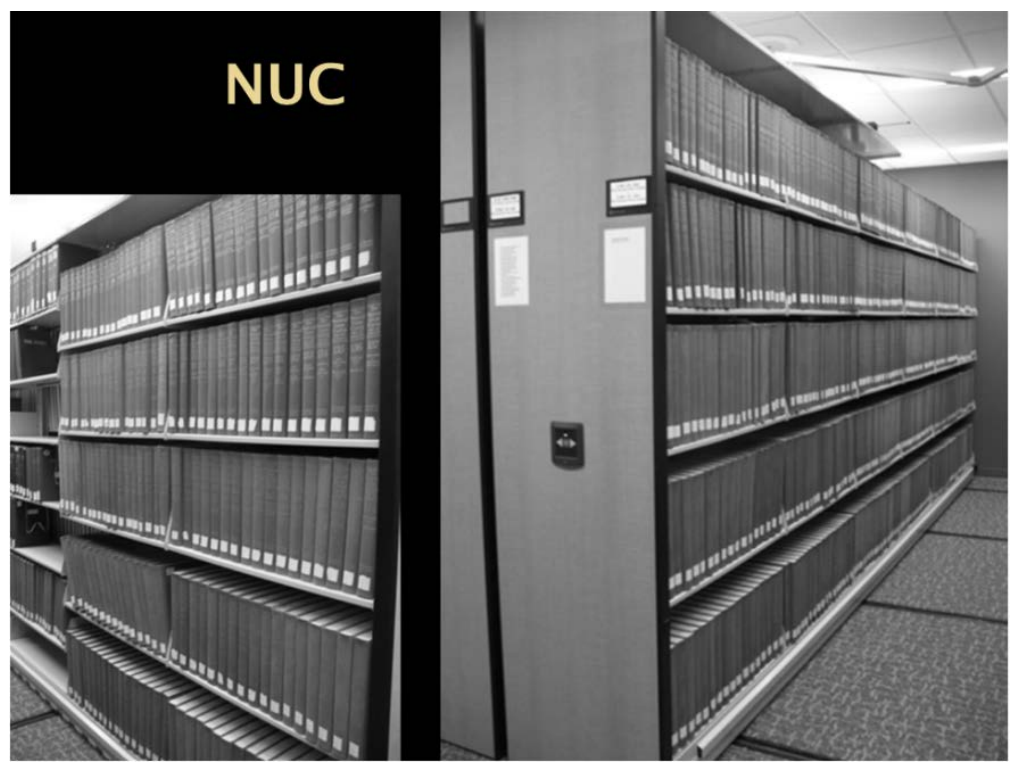

Figure 1. National Union Catalog

Created at the end of the analog-only age, the NUC's production was an unprecedented 14-year effort on two continents to amass the author-title cards of imprints prior to 1956 from the catalogs of major North American research libraries. The NUC served as a catalog copy source, an interlibrary loan finding aid, and a reference tool for librarians and researchers. After the NUC's and one-quarter had discarded the set. The Keepers generally had larger budgets and few immediate space concerns. The Discarders had smaller budgets and were more likely to respond that they had pressing space concerns. The Discarders appeared to have fewer options in accommodating new demands on their library's space. 
The Keepers retained the set because of concerns that WorldCat lacked all the NUC entries, thought researchers may still use it, and in recognition of the expense and iconic status of the NUC. Almost all the Discarders thought the set was no longer used by their patrons, needed the space for other purposes, and could obtain needed volumes from interlibrary loan. The Keepers responded that known NUC users included:

$\begin{array}{ll}\text { Known NUC users? (selected all that apply) } \\ \text { Lib staff } & 57 \% \\ \text { Faculty } & 37 \% \\ \text { Graduate Students } & 12 \% \\ \text { Undergraduates } & 2 \% \\ \text { Other users } & 14 \% \\ \text { Do not know } & 33 \%\end{array}$

However, more than $40 \%$ of the Keeper respondents estimated that the NUC was never used in the last year, and 30\%estimated only one to five uses in that year. In both groups, current accessions included very few pre-1956 imprints, with Discarders reporting essentially no works older than 1956 acquired and needing cataloging copy. Cataloging librarian respondents favored retention of the NUC twice as often as collection management respondents.

The majority of Discarders (62\%) had removed the NUC in the last five years. The ultimate fates included:

$\begin{array}{ll}\text { Recycled } & 54 \% \\ \text { Found home in another library } & 15 \% \\ \text { Other [not sure, state surplus, etc.] } & 31 \%\end{array}$

Public perception of discarding the NUC was thought by the authors to be a factor in retention. However, only $12 \%$ of Keepers worried about a public relations backlash if the NUC was discarded. Among Discarders, 85\% reported no regrets with the decision to discard the NUC.

\section{Conclusion}

Using the NUC as a representative of the various large, pre-digital sets needed to be examined for possible discard, it is difficult to identify compelling trends in the decisions to keep or discard. Retention by the Keeper respondents is not based on: (1) use of the set by the campus; (2) pressing collection management or cataloging needs; or (3) possible public reaction to the NUC's removal. The collection management decision to retain the NUC appeared to be based on the lack of a sufficiently competitive demand for the space the set occupies. Cataloging librarians are more likely to wish to retain the set just in case there is a pre-1956 imprint.

An interesting counter-current in academic libraries may forestall the disposal of these sets. Current physical accessions may be reduced in number by the growing proportional shift in acquisition away from space-taking paper books and towards e-books. Confidence in JSTOR and Portico/LOCKSS stability may speed the removal of physical journal volumes as well, opening other space for repurposed uses.

The NUC and the other pre-digital age sets may continue to be held in midsize libraries, in part, because of inertia and lack of competing space demands. But where space is an issue, many midsize library libraries will choose to discard unused pre-digital paper sets, such as the NUC. The generations of librarians who used the NUC and other analog sets are passing from the scene in academic libraries, and the incoming digital native librarian knows little or nothing about them. An examination of current textbooks in collection management and cataloging, for example, reveals scant mention of the NUC. Similar trends may exist for newly-trained scholars in English and history who once relied on such tools as the final rocks to look under for answers to age-old questions.

Midsize libraries, comfortable in the diligence of R-1 research libraries to thoroughly retain the more obscure pre-digital finding tools, will increasingly find their own way in building midsize library collections. These collections will balance the research needs of midsize institution faculty and students against the demands of midsize library space and budgets. 